\title{
Empowering students to promote independent learning: A project utilising coaching approaches to support learning and personal development.
}

\section{Dawne Gurbutt}

University of Central Lancashire, UK

\section{Russell Gurbutt}

University of Leeds, UK

\section{Abstract}

With the publication of the UK White Paper (BIS, 2011) focusing on student experience, together with the increase in tuition fees and the changing landscape of higher education, there is an interest within the sector to explore initiatives that enhance the learning process. Coaching, as already used in management and some NHS settings, offers an approach which seeks to enable and empower learners and has the potential to contribute to their personal development, facilitating solution-focused approaches which are transferable to the workplace.

Teaching staff in a Higher Education Institution were offered training in coaching techniques and formed a peer support coaching network. They were subsequently encouraged to use coaching skills in a range of student settings. This paper focuses on an evaluation of a teaching and learning initiative that used coaching approaches with two groups of healthcare students (totalling 19) over 2 semesters in the 2012-2013 academic year. The aim was to enhance the student experience in relation to self-motivation, personal development planning and the development of solution-focused approaches. The evaluation drew upon student feedback and conversations with staff in the coaching network. 
The evaluation highlighted the benefits of coaching; student preferences and expectations; new learning experiences of staff and the relevance of coaching approaches in other specific educational settings. The evaluation demonstrated how coaching adds value; providing students with the opportunity to develop workplace skills; and offering staff a solution-focused tool which may be particularly useful when facing change in workplace settings. Importantly it gives participants a creative space to engage with contemporary challenges and educators a 'new' tool to facilitate participation and nurture engagement in a non-directive way.

Keywords: coaching; student experience; empowerment; learning engagement.

\section{Introduction}

The changing landscape of higher education has placed renewed emphasis on enhancing the student experience. Indeed this has been articulated as a requirement:

Institutions must deliver a better student experience; improving teaching, assessment, feedback and preparation for the world of work. (BIS UK White Paper, 2011, p.4).

This has particular relevance when undertaking educational initiatives for healthcare sector roles that require students to be self-reliant and solution-focused. A lack of such learning can be detected in practice, for example in the reported failings of an NHS Trust:

There are places where unhealthy cultures, poor leadership, and an acceptance of poor standards are too prevalent. (Frances, 2013, p.25).

Failures in learning how to perform to acceptable standards are also noted in the Nursing and Midwifery Council's 'Fitness to Practise Report' (NMC, 2013): issues included misconduct (63\%) and lack of competence (17\%). This performance deficit also highlights clear implications for service providers, regarding continuing personal development in problem solving and goal attainment, with a consequential impact on service users. 
Given this context and the promotion of lifelong learning in practice, where individuals own their professional development rather than act as mere consumers of discrete 'packets' of education, a requirement remains to continually explore ways of facilitating a better student experience across a diverse learning population. Whilst reflective practice, inservice training and accredited post registration courses all have their place, a coaching approach has something new to offer. It has a role to play in developing individualised learning (so having direct real world relevance) and also promotes learning ownership so strengthening the potential for engagement in learning contracts.

Teachers in Health and Social Care disciplines already draw on a range of strategies to transfer their practice-based skills into education (such as problem based learning) whilst maintaining a real world focus. This can also include coaching approaches already used in management, organisational and life coaching settings over recent years (Parker et al., 2008). It is appropriate therefore, to briefly define coaching.

\section{What is coaching?}

Coaching is defined in different ways but the European Coaching and Mentoring Council states:

Coaching and Mentoring are developmental activities within relationships based on trust and established through conversations [which] aim to develop the personal or professional competencies of the client. (European Coaching and Mentoring Council, 2013, p.1).

Different models exist to represent exactly how the activity is undertaken and some commonality exists as to essential elements of coaching. Its purpose varies. Downey describes effective coaching as:

A pre-dominantly 'non-directive' approach, an approach that evokes excellence, in which learning is intrinsic and satisfaction derives from the pursuit and achievement of meaningful goals. (Downey, 2003, p.19) 
Others highlight need, 'focusing on what clients want' (Whitworth et al., 1998, p.8) or 'making changes' and moving from 'imagination to reality' (O'Connor and Lages, 2004, p.4), as well as personal enrichment, 'building awareness' and 'unlocking potential' (Whitmore, 2002, p.8). Overall learner-centric, development and goal attainment elements resonate clearly with the aims of personal development planning within higher education and health and social care.

Coaching and counselling can sometimes be viewed as similar, sharing many skills - in particular listening and asking questions. However there are distinctions. Coaching entails consideration of the individual, the task and the context, whereas counselling focuses therapeutically on the individual and their context and is often remedial, in pursuit of 'wholeness'. The emphasis of coaching by contrast is on learning and development (Downey, 2003, p.200). Stevens (2008, p.8) goes onto contrast counselling and coaching via central underpinning questions: 'therapy asks 'why me / why this?' whereas coaching focuses on "what next/ what now?" The role of the coach is therefore to move the coachee forward, helping them to find solutions and identify ways to achieve goals. Appreciating these differences aids awareness of which approach is more appropriate in a given setting. Settings in which coaching skills are used include management situations when focusing on tasks achievement. In a similar way it is used in education to support personal development planning and individual formulation of personal learning goals. Additionally within learning development it is used to compliment lectures and other forms of educational provision.

\section{Coaching approaches}

There are different theories and models of coaching, the SIMPLE and GROW models will be discussed and are summarised in Figure 1. The SIMPLE model is a solution-focused, client-centred approach, which outlines the principles of coaching (Jackson and McKergow, 2007, p.10). 
Figure 1. Two coaching models.

\section{The Simple Model (Jackson \& McKergow, 2007)}

\section{S - Solutions}

In the coaching context, the solution is what the client wants. The coaching conversation focuses on solutions rather than problems, whilst not ignoring or dismissing problems. Coaching works on the client's agenda rather than the coach's agenda.

\section{I - In between}

When coaching, the coach works with what is being said by the client, as opposed to his/her interpretation of what is being said. The action comes from the interaction between the coach and the client. The role of the coach is non-judgmental.

\section{M - Making use of what is there}

When working with a client towards their solution, find out what is already working and what has worked in the past (or in other situations) and build on it. Part of the solution may be happening already and the role of the coach would therefore be to ask questions that reveal and 'illuminate' the client's own solution.

\section{P - Possibilities}

When coaching, help the client look for possibilities in the past, present or future.

Generating possibilities helps the client to find the next step. Coaches believe clients are resourceful and the role of the coach is to draw out the answers.

\section{L - Language}

Keep language clear and as simple as possible: break down the words used to ensure clarity e.g. delegation - what will be happening if your delegation improves? How will you know? As a coach, ensure you understand what the client means by the words they are using.

\section{E - Every Case is Different}

Every coaching situation will be different; therefore helping clients generate the right actions for them is of more value than suggestions. There is a place for the coach's ideas but ask for the client's ideas first, adding yours afterwards if requested by the client. 


\section{The Grow Model (Whitmore, 1992)}

\section{G - Goal}

A discussion of what the desired outcome is and articulating the goal in a specific and measurable way so that the coachee can tell when it has been achieved. Additionally it is owned as a goal by the coachee.

\section{R - Reality}

An exploration of the current position and where the coachee wants to be. At this stage the coach encourages the coachee to be specific by asking questions to challenge them to really review their situation.

\section{O - Options}

Once the destination is clear, discussion moves to an examination of the options available. Time spent exploring all avenues is valuable, weighing up the pros and cons of each.

\section{W - Way forward}

At this stage the coachee is asked to identify the specific actions required to move forward with the chosen option in order to achieve the goal. This is a choice that the coachee can commit to and own the progression process.

Implicit in the 'simple model' is the notion of 'in-between'; i.e. working with what is said by the client and not on the interpretation of what is being said, or the prior 'knowledge' of the coach - this is a challenge when working with coachees within a familiar context or who are known to the coach. There are similarities to be drawn with the practice of phenomenology in qualitative research which suggests that 'bracketing out' (Holloway, 1997 ) the self is possible in research contexts, though it could be argued that this is never fully achievable. An awareness of the need to focus entirely and exclusively on what is being said, and not on existing knowledge, helps to identify prior knowledge and assumptions that affect the discussion and so consciously avoid this 'interference'.

The concise GROW model focuses on Goal, Reality, Options and Way Forward (Whitmore, 1992). Downey (2003, p.25) includes a 'Topic' element, based on initial understanding as a precursor to the GROW process. The GROW model was considered as more appropriate for education and health settings, as 'problem solving' and 'goal oriented work' characterises aspects of care management and client interaction. 
Consideration can be given to other models and approaches, such as the Coaches Training Institute's 'co-active' coaching model (Stevens, 2008, p.108) which focuses upon 'Who? What? Why?'. Alternatively, Neuro Linguistic Programming (NLP) approaches focus on a 'journey' that begins with goal setting and progresses through to an action plan (O’Connor and Lages, 2004, p.28-31).

There are many resources that cultivate skills development within a coaching framework. The co-active coaching approach proved a useful source from which some skills and approaches could be 'borrowed' as resources for coaching practice. Whitworth et al. identify four cornerstones;

Viewing the client as naturally creative and resourceful, addressing the client's whole life, the agenda coming from the client and the relationship as a designed alliance.

[The] designed alliance is customised to meet the exclusive needs of the client....and both players are involved in making it work.

(Whitworth et al., 1998, p.3;13).

This approach, in common with many others, aims to develop particular skills in the coach which include listening (described as 'a striking experience partly because it is so rare') (Whitworth et al., 1998, p.31); intuition; curiosity; action learning and self-management. These can be contrasted with other skills identified as core to coaching such as;

Rapport...questioning, communication etc. (Stevens, 2008, p.25-42).

\section{A coaching evaluation}

Following a postgraduate course in 'coaching within management settings' sponsored by the employer, personal interest turned to considering possible wider applications in educational settings. This was encouraged across the university through peer discussion via a new in-house coaching network that enabled staff from different disciplines to develop their coaching skills and identify new coaching applications. 
A small-scale evaluation of a coaching activity, used as a teaching and learning approach in two different modules, was undertaken over two semesters during the 2012-13 academic year. The University's' Academic Quality Assurance framework, section 14.1, allowed for module learning evaluations 'through a variety of methods' to analyse areas where high standards exist and to help identify those areas indicating a need for quality improvement (University of Central Lancashire, 2013, p.17). This process included qualitative feedback collection at a module level, including verbal feedback to module tutors. The provision of anonymised evaluation feedback was thus authorised for use in published reports and governed under the local research ethics regulations.

The coaching learning and development evaluation involved participants on two different undergraduate health studies modules (i) Group 1: four students completing a supervised self-directed study module which would lend itself to enhance their learning experience via promoting individual engagement, learning goal creation and ownership and (ii) Group 2: fifteen top-up degree students used action learning approaches in monthly meetings relating to engagement with course management issues within a coaching framework.

The process for both groups involved four steps; introduction; coaching; reflection and group discussion. Initially the students were introduced to the models and the ways in which coaching approaches could be used and were then given some experience of being coached. Given that all module delivery is routinely evaluated by students the idea of reflecting on their learning experience at the end of each session as part of the supervision process would also include their reflections on reactions to using coaching approaches. They were also asked to evaluate the process at the end of the semester when assignments had been submitted. At that time a participant discussion group was held to evaluate their responses to the approach and particular coaching elements that had been used. This feedback contributed to considering how elements of coaching could be used in other settings that involved solution-based approaches to problem solving, behaviour change and personal development. Qualitative comments were recorded during the evaluation by notes made during action learning set conversations, 'post-it' note activities where students recorded and clustered their feedback onto a board and also the university module feedback forms. 


\section{Learning from the evaluation}

A range of points emerged from the evaluation including helpful outcomes; preferences when using the GROW and SIMPLE models; dislike for coaching; and staff perspectives on the relevance of coaching to their work.

Several outcomes were seen as helpful including the goal setting focus; identifying resources and steps to take as a way of moving forward (all of which were implicit in the GROW model). Likewise 'being in the moment' and a 'solution-focus' were complemented via the SIMPLE approach which supported affirmation. Scaling was another coaching element used, in which the coach asked the individual to gauge the importance of an issue or action on a 1-10 scale and then determine where they would like to be on the scale. In this way the coachee could focus on how to move to the next step and make progress towards identified goals. Instrumental in this approach was a sense of getting the coachee to identify 'what success looks like' for them.

The grow model was primarily used with group 1 (self-directed study group) on a one-toone basis. They found the 'goal' setting element quite useful. One participant commented:

At first I thought it was quite obvious - the goal was to get my dissertation done, but then the coaching questions kept pushing me to be more specific and I began to focus on how the dissertations would help my future career (which influenced my choice of topic) and also identified interim goals.

Whilst another participant commented positively:

I don't ever think in goals, so it seemed really good to really think about what I was aiming at...it made more sense of the timeline.

However more students commented on the 'reality' part of the coaching:

I am used to compartmentalising my life - this approach made me realise just how much my part-time job, social life and living away from home impact on the reality of how I study. 
Another stated:

We got into a coaching conversation about motivation and self-motivation: I realised that the things that motivated me at school are absent at university, [which] maybe explains some of the issues I have been having.

Some learning benefits exist here for educators; appreciating the value of focus and nurture over prescription concerning learning goals, and for students; adopting a holistic approach to their life, of which learning is a part. In this way there might be a more sustainable route into life-long learning.

Other comments related to the 'options' stage of the GROW model. It is implicit in the coaching process that the coach does not suggest options, but that these exclusively arise from the coachee. Therefore a useful tool when coaching is to ask the 'what else?' question, as illustrated in the following student's comments:

She just kept asking - what else? What else? And I was annoyed at first and kept thinking 'that's it', but actually the further we went on the more stuff I kept thinking of and I felt I went from no options (in solving a problem which had emerged in the research) to feeling that there were actually things I could do.

Another stated:

We were talking about where I could get support and I suddenly became aware of all sorts of places in the uni; old friends; roommates; even my mum. It opened up all sorts of possibilities.

Others commented on 'the importance of thinking about the resources available'.

The final step of the GROW model, the 'way forward', involves identifying one action. A participant commented on their sense of obligation:

I felt I had to do it before I went back to my next supervision because I had suggested it (as an action). 
Another remarked on changing expectations that required them to take ownership:

I was annoyed at first. I went for tutorial because I wanted her to tell me what to do and she didn't, she made me work it out myself. Once I had got over being annoyed, I felt quite good about it all.

Whilst another commented on their transition from passivity:

I realised I was happy talking ideas, but I didn't want to be pinned down to actually doing stuff. In the end I pinned myself down.

Whilst another said:

It was so helpful that I found myself having imaginary conversations with myself between supervision sessions in which I thought about the stages and the questions.

This transition from theory to practise was captured in the following comment:

Written down it all seems obvious and simple, but it is really empowering.

In line with earlier remarks favouring nurture over prescription, probing questions serve to facilitate engagement that ultimately helps the individual make a transition from passivity, as a consumer of information sufficient to complete an assignment, to identifying what they need to integrate into personal learning to achieve the intended outcomes.

The SIMPLE model was used in personal tutorial settings where, as a personal tutor, the topics raised were often familiar and repeated, as students were confronted with similar issues. Although as the SIMPLE model highlights, in reality 'every case is different' and that is true as far as each student finds their own response to these issues. Participants reported benefits of a solutions focus that: 'helped me to move it on'; and helped people 'to get unstuck'; 'it stopped me from keep telling my story and beating around the bush to moving to the next stage - right it has happened, now what am I going to do?' 
Group 2 used action-learning approaches in which each person in the group has individual 'air time' (a meeting where each person has individual uninterrupted space to speak in a group meeting). In the following comments, during a staff/student liaison meeting that utilised a solutions-focused approach to address the difficulties in being situated 'off-site' from the main campus, points of engagement emerged. One student commented:

I was sitting in the circle and I really didn't want it to come around to me, but when I shared my idea people liked it and it actually felt great.

Another said:

People really listened to me, I am quite shy so it was a new experience, and it wasn't half bad.

A further comment was:

It made me contribute and I don't usually do that and I found I had something to say.

Reflection on engagement gave rise to comments about a lack of self-confidence, not seeing oneself as a contributor or just enjoying being heard. Being heard was valued as part of the process with one participant commenting:

It was ultra-polite, no one was shouted down or drowned out.

In one way or another most participants commented on the benefits of listening and focusing on the individual or coachee in a solution-based session: this benefit is in its impact on learning development and its ability to unlock potential and growth in a seemingly short condensed activity that engenders learning momentum.

There are times when coaching is not the best tool and when other approaches, which are either more directive or more therapeutic, might be more appropriate. Sometimes individuals are just resistant to being coached. However Stevens (2008, p.98;125) suggests that sometimes it can help for people to identify their 'gremlins', i.e. the things that make them resistant to being coached. 
Those who didn't like coaching commented that: 'It just feels like it is taking too long to get anywhere' and: 'I just didn't like it. I felt it was all moving too slowly'. Another participant said:

I didn't feel comfortable, but maybe it was actually one to one supervision sessions I don't like, I felt exposed somehow.

Resistance in itself is a learning point for educators too, as it highlights the need for an intervention that can manoeuvre learning beyond an impasse.

Conversations with the university coaching network staff who were trialling coaching with students felt that it enhanced their work as it was:

Centred on listening and communication skills in one way or another.

Some commented that coaching rekindled enthusiasm for reflecting on and evaluating communication skills. Others commented positively how coaching and an awareness of coaching models had expanded their existing skills and increased their knowledge of different techniques. Some noted how their level of creativity released through coaching was 'sometimes surprising'. There appeared to be a range of different applications and responses to coaching emerging from the coaching network group including immediate and longer-term feedback from people who were known to the coach.

Health care staff within the network reported that they felt comfortable with the GROW model from the outset. The process stages were easy to learn and internalise and the model had an internal progression to it, which was reported as feeling 'very natural and unforced'. They also liked the term 'GROW' as it was a reminder of the underpinning values of coaching - to grow and develop the coachee, in this case the student.

When thinking about whether coaching would be beneficial in other contexts, some saw advantages:

A solutions focus cannot be a bad thing and identifying a range of resources can only be positive. 
Others expressed doubt including:

I think it would take too long to explain to larger groups of students what coaching is about. It would be too time consuming and I don't think you could get them to engage enough to consent to being coached.

However, there was some agreement that the types of questions used in coaching are helpful:

Focusing on the present rather than the past and getting the person to a place where they acknowledge where they actually are, rather than where they would like to be.

Overall these comments indicate that coaching can add value regarding communication skills development (especially relevant on professional registration courses), and offer learning opportunities for educators who can perhaps experience refreshing insights into what might have become familiar patterns in student encounters.

\section{Conclusion}

Whilst being a small-scale, module-based evaluation, the learning suggests that there is merit in undertaking a larger evaluation study and to consider measurable impacts on achievement and student satisfaction if implemented as a consistent strategy across a programme. Such a move could allow students to become adept at being coached beyond a single module experience and consider how to develop elements of coaching in their own practise such as with goal related patient interactions.

Coaching has the potential to deliver real benefit in educational contexts, as it does in management contexts, fusing successful goal achievement with growth, learning and development. Although there may be occasions when it may not be directly applicable, the repertoire of coaching skills are relevant to good management and support, offering tangible benefits at a personal level for students and also teaching teams. 
Coaching adds value; providing students with the opportunity to develop workplace skills; and offering staff a solution-focused tool which may be particularly useful when facing change in workplace settings. Importantly it gives participants a creative space to engage with contemporary challenges and educators a 'new' tool to facilitate participation and nurture engagement in a non-directive way.

Overall the experience of implementing 'personal learning' to enhance the student experience is a reciprocal process that engenders thought about its appropriateness to student preferences and different tasks. It also has broader implications for the provision of institutional support to draw staff in to using coaching approaches as a means of enhancing student experience.

\section{References}

BIS (2011) Higher Education: Students at the Heart of the System, Department for Business Innovation and Skills (BIS) White Paper, June. Available at: https://www.gov.uk/government/uploads/system/uploads/attachment_data/file/3138 4/11-944-higher-education-students-at-heart-of-system.pdf. (Accessed: 2 October 2014).

Downey, M. (2003) Effective coaching: lessons from the coach's coach. $2^{\text {nd }}$ edn. London: Texere.

European Mentoring and Coaching Council (2013) Definitions for coaching and mentoring. Available at:

http://www.emccouncil.org/webimages/CH/Aldo/Glossary Coaching Mentoring E MCC Switzerland en 20.05.13.pdf (Accessed: 2 October 2014).

Frances, R. (2013) Report of the Mid Staffordshire NHS Foundation Trust Public Inquiry, Executive Summary, February. Available at: http://www.midstaffspublicinquiry.com/sites/default/files/report/Executive\%20summa ry.pdf (Accessed: 2 October 2014). 
Holloway, I. (1997) Basic concepts for qualitative research. London: Blackwell.

Jackson, P.Z. and McKergow, M. (2007) The solutions focus. Making coaching and change simple. Boston: Nicholas Brealey Publishing.

Nursing and Midwifery Council (2013) Annual Fitness to Practise Report 2012-2013, October. Available at: http://www.nmcuk.org/Documents/Annual reports and accounts/Annual\%20Fitness\%20to\%20Pra ctise\%20Report\%202012\%20-\%202013.PDF (Accessed: 2 October 2014).

O'Connor, J. and Lages, A. (2004) Coaching with NLP. London: Element.

Stevens, N. (2008) Learning to coach: the skills you need to coach for personal and professional development. $2^{\text {nd }}$ edn. Oxford: How To Books.

Parker, P., Hall, D.T. and Kram, K.E. (2008) 'Peer coaching: a relational process for accelerating career learning', Academy of Management Learning and Education, 7(4), pp. 487-503.

University of Central Lancashire (2013) Academic quality assurance manual. Available at: https://www.uclan.ac.uk/students/research/files/AQA Manual 2013 14.pdf (Accessed: 2 October 2014).

Whitmore, J. (1992) Coaching for performance: A practical guide to growing your own skills (people skills for professionals). Boston: Nicholas Brealey Publishing.

Whitmore, J. (2002) Coaching for performance: growing people, performance and purpose. $3^{\text {rd }}$ edn. Boston: Nicholas Brealey Publishing.

Whitworth, L, Kimsey-House, H., Sandahl, P. (1998) Co-Active coaching: new skills for coaching people toward success in work and life. Alto, CA: Davies Black Publishing. 


\section{Author details}

Dawne Gurbutt has a PhD from Lancaster University (2004). She is a Principal Lecturer in the School of Health at the University of Central Lancashire.

Russell Gurbutt has a PhD from the University of Central Lancashire and is a Lecturer in the School of Healthcare at Leeds University. 